\title{
Gendering of Time Management: Perceptions and Experiences of Working Women
}

\author{
Jackson Adams., PhD \\ khala@essex.ac.uk, jacksonadams63@gmail.com \\ Essex Business School \& The School of Law, University of Essex, United Kingdom \\ Nouha Almahmoud., PhD \\ dr.nouha.almahmoud@gulfuniversity.edu.bh \\ Assistant Professor in Management, \\ College of Administrative and Financial Sciences, Sanad, Kingdom of Bahrain
}

\begin{abstract}
Understanding and experiencing time has been historically and socially formed by various bodies of power and control who have advocated commodifying clock time of the capitalist economy. This has significantly impacted the lives of working people in general and working women with care and domestic duties in particular. So, many studies have demonstrated the gendering of time management in the Western workplace, but none so far - to the best of the authors' knowledge - has been reported in the Middle Eastern countries in general and in Syria in particular. Here comes the contribution of this study, which investigates a sample of Syrian women with paid work duties by conducting in-depth, face-to-face, semi-structured interviews.

The investigation explores the individual perceptions of time as well as the individual experiences of time management regarding the participants' paid and unpaid work duties. The focus here is on identifying and explaining the internal and external factors which drive the participants' perceptions and experiences.

The interview narratives have revealed that time management is gendered - it requires women rather than men to strike a balance between their employment role and domestic role. However, not all participants were aware of the boundaries between time spent on public paid work and time dedicated for private unpaid or domestic work. In conclusion, the study has demonstrated that gendered time allocation is culturally embedded through gendering domestic and care work, which affected the time spent on paid work in the public sphere.
\end{abstract}

Keywords: time management, time allocaton, work, gender, cultural norms

\section{Introduction}

Organisations and working people have always looked for effective methods and techniques for managing or organising time in order to increase productivity. Although time was believed to be a finite resource that can be commodified, the understanding of time has been historically and socially formed by various bodies of power and control who have advocated commodifying clock time of the capitalist economy (see Durkheim cited in Gell, 2000). So, according to Goudsblom (2001: 20) time is:

A socio-cultural construction which aids people inntheir efforts to collectively orient themselves in the world and to co-ordinate their activity

With the rise of capitalism and industrialisation, the modern time of waged workers, who were paid according to how long they worked, was born (Adam, 2004). Here, time became equated with money and could be measured, bought, sold, invested, wasted and saved; as clearly expressed by Max Weber, quoting Benjamin Franklin's phrase ‘time is money' (Weber, 1965 [1999]: 48). This view of time came in line with "the Newtonian concept of time as something objective, measurable, divisible and independent of any observer's experience, activity, perception or memory" (Bryson, 2007:26). In the capitalist sense of time, "all time must be consumed, marketed, put to use; it is offensive for the labour force merely to "pass the time"" (Thompson, 1999:395). Hence, leisure time was seen as unprofitable and morally depraved; and this has caused a change in the mindset of both men and women,

The current issue and full text archive of this journal is available at www.jraspublications.org/index.php/JRAS/issue/archive Journal of Research in Administrative Sciences (JRAS) V IX(II), 28-35, ISSN: 2664-2433 who started using their current time to improve their future living standards. This has contributed to the loss of freely chosen activity or leisure time from the lives of hard workers; and at the same time made women and men inhibit different cultures.

For the current study, the researcher has chosen not to focus purely on the notion of time per se, but rather to investigate the impact of gender on the understanding of and dealing with the concept of time in a specific culture - Syrian. The primary research question of the current investigation is: "How is time allocated by working women?". This leads to other sub-questions, namely:

1. What is the impact of cultural norms on women's time allocation in and outside the workplace?

2. How do managerial practices affect women's time management?

The contribution of the study is based on the researchers' belief derived from an extensive research done - that there is no previous attempt to investigate working women in Syria in relation to organising work time.

As for the structure of this study, there are five sections, organised as follows: Section (1) has introduced the notion of 'time' and the proposed topic. Section (2) will review prior studies on the notion of 'time' and its gendered management. Section (3) will present the findings, analysis and discussion. Section (4) will be dedicated for conclusions, limitations and recommendations of this study. 


\section{Prior Research}

Organisational research has demonstrated a significant interest in investigating the concept of time management and its impacts on the production process as well as the workers' lives (see Hofstede, 2001; Eriksen, 2001; Hassard, 2002; Greenhouse and Powell, 2003; Adam, 2004; Warf, 2017; Hassan, 2009; Rosa \& Scheuerman, 2009; Ylijoki, 2010; Ancori, 2019; Scheuerman, 2020).. For instance, the interest in managing the production time

of workers was one of the factors that led Frederick Taylor in the late nineteenth century to lay down his methods of 'Scientific Management' (Calabrese, 2018). It was an attempt to achieve efficiency, predictability and control in the industrial workplace within a specific limited time frame. In this sense, time has been de-contextualised as a quantifiable, standardised and universal unit of measurement, and conceptualised as a currency that can be spent and exchanged in ways similar to money.

As for the literature on 'time management', it has demonstrated that conformity to gendered time norms has contributed to maintaining an unequal division of the domestic and workplace labour (Evertsson \& Nermo, 2004; Cast and Bird 2005; Bryson, 2007; Sabelis et al., 2008; Bouffartigue, 2010; England, 2011). Therefore, some researchers have contemplated that gendered temporal arrangements are historically and socially produced and maintained by human agents over time, and they are open to challenge and change (Purser and Hassan, 2007; Fagan et al., 2008; Amanatullah \& Morris, 2010). Having said that, it is worth mentioning that 'men' and 'women' are not closed, stable or unified groups and that the meaning of woman or man is socially constructed. For instance, the experience of being a woman or a man is qualitatively different for people in different class positions and from different ethnic groups. Thus, being a woman with caring responsibilities leads women to see time as inherently relational, something that is shared and negotiated with others, while men see it as something for individuals to own and use as they wish (Bryson, 2007). However, Lister (2007) has noted here that some feminist scholars advocate that gender can be multiple, fluid and freely chosen, rather than the stable core of our identity - yet, it can be maintained only by 'gender-appropriate behaviour' (Bryson, 2007: 57). For instance, , time spent in paid work is seen as rationally chosen activity in the public sphere and valued because of its association with the mind, while time spent caring for family members is seen as emotionally driven, devalued because of its association with reproduction and the body and the invisible work (Prokhovnik, 2002: 13).

The following sections of prior research will briefly outline the concept of 'time' through the academic lens, and how 'time management' was experienced by working women and investigated by various research strands.

\section{The Notion of 'Time' in Prior Studies}

Historically, clock-time represents a standardized, uniform, quantifiable and linear timeframe typical of modern organizations. This clock-time has been accelerated by the neoliberal globalization of the markets and the advances in new information technology, and consequently, the pace of life and work has become more and more hectic, with no time for careful planning and democratic debates about the future line of action (Ylijoki, 2010). The acceleration has affected contemporary society and has been later researched through three different perspectives: (a) technological - the speeding-up of transportation, communication and production; (b) Social - the rapid change in social relations, values and lifestyles; and (c) cultural - the speeding-up of the pace of all sorts of activities (e.g., plays and television series, the life cycle of books and fashions) (see Ancori, 2019; Scheuerman, 2020). The overall temporal acceleration has been described as 'fast time' - which is contrasting with the notion of 'slow time' that imparts features such as security, predictability, belonging, coherence and cumulative and linear growth; fast time is claimed to be colonizing slow time whenever possible (Eriksen, 2001).

With the advances of technology, researchers have identified the concept of 'network-time' which refers to digitally compressed clock-time and which seems to be more dictatorial than clocktime since it is unpredictable, volatile and chaotic (see Hassan, 2003). This network-time 'is beginning to displace, neutralize, sublimate and otherwise upset other temporal relationships in our work, home and leisure environments' (Ibid, 2003: 235). This increases the risk level in activity, especially as the organizational environment has become more complex (Sabelis, 2004). For instance, Hassan (2003: 237) claims that reflexive knowledge becomes increasingly difficult, as 'there is simply less time for it and less perceived need for it in an increasingly competitive and profit-driven social-economic system'. According to him, acceleration leads to 'abbreviated thinking' and instrumental knowledge focused on the here-and-now - the result of which is a focus on the 'culture of short-termism' (Hassard, 2002). Therefore, research attention was directed to the speed of time and its role in society (Hassan, 2009; Rosa \& Scheuerman, 2009; and Warf, 2017). Time-space compression has affected social orders and transformed people's understandings of their world (Crang, 2010: 405). Here, the network has accelerated the production process, eliminating the horizons and disconnecting us from local temporalities (Hassan, 2009). For example, the electronic mail has already changed the rhythm of work and made people less sensitive to international time-zone differences. Thus, information technology (IT) is causing changes in the time-frame patterns: it eliminates rigidity in work rhythm and gives more flexibility. The Internet is always on, enabling 24-hour work across geographical dispersed areas as well as temporally dispersed users. It has also enabled us to renegotiate the structure of deadlines, increasing the compression of time and space (Warf, 2017). Here, time has become a competitive issue, enabling the shift from the economies of scales to economies of time since what matters in the modern business world is the speed of responsiveness of an organisation (Linstead et al., 2009).

Proponents of globalisation have also called on researching the cultural perspective of 'time' as they stressed the convergence of national cultures with the spread of global marketing. For example, Hall (1990) has considered time as an important cultural difference, and Hofstede (2001) has identified long-term versus short-term time orientation as a cultural difference since different cultures show different attitudes towards time. Along these lines, Marcus and Gould (2000) have advocated that cultural relativism is necessary in managing the modern workplace, especially in international organisations. Thus, the concept of time seems to be causing differences between people's orientation to the past, present or future and between long- and short-time horizons (Newell and Scarbrough, 2002). Therefore, managing time in globalised/internationalised companies is quite challenging. For instance, a culture could be monochronic or polychronic (Solomon and Schell, 2009). A monochronic culture believes that time is linear and emphasises scheduling and promptness, where people do things one at a time and "see time as a commodity that can be measured, used and sometimes sold" (Steers et al, 2010: 62 ); while a polychronic culture has non-linear approach to time since it "believes that interaction with others and relationships are the most important things" (Solomon and Schell, 2009:181), and therefore addressing several problems simultaneously and resisting firm deadlines. Thus, researching time management is not a straightforward process because of the fact that time is often compounded by other dimensions, such as culture and gender (Steers et al, 2010). The attitudes towards time can be described as an "invisible factor that makes culture visible through visible behaviours" (Solomon \& Schell, 2009: 47).

On the other hand, Greenhouse and Powell (2003: 93) argued that in any society "Meanings of time are themselves variable and unsettled"; and Adam (2004) has argued that any individual in any society inhibits a multiplicity of time cultures and at any moment we are never simply in the present but also in the past and future. This has overturned the Newtonian concept of time as objectively measurable (Bluedorn, 2002). The technological advancements (such as mobile phones and emails) have made commodified clock time intruding into every area of life, blurring the boundaries between home and work. Therefore, Adam (1995: 94) has clearly protested against commodification of time, pointing out that:

Not all time is money. Not all human relations are exclusively governed by the rationalized time of the clock. Not all times are equal. 
This tendency of time commodification has led to the emergence of overwork culture that resulted from the clash of "two different time frames: the 'timelessness' required by employers and the 'timeliness' required by intimate relationships", as identified by Bunting (2011: 16). In this overwork culture, workers are seen as 'willing slaves' prepared to work ever-longer hours in a society that equates busyness with success and status (Ibid, 215-16). Other researchers (e.g., Hochschild, 1997; Putman, 2000) have claimed that the overwork culture has affected family and community life, leading towards not only the parent-free home, but also the participation-free civic society and the citizen-free democracy (Hochschild, 1997: 243). Eventually, in their different fight against time and commodified clock time, contemporary employers and employees debated various policies around parental leave and flexible employment.

In brief, the question which poses itself here is "how do people manage their work times and their non-work times?", and whether they have any control over the process of time management and time allocation. In measuring work time, employers are the ones who control their employee's time since they are the ones who decide the income of that employee. Therefore, time spent at work (paid or unpaid) will adversely affect the non-work time (domestic and leisure), and free time will be affected by time spent on paid and unpaid work. Hence, feminist scholars have started campaigning for quantitative studies to measure the time spent on unpaid work in an attempt to accord it with a monetary value and to identify its distribution between women and men (Bryson, 2007:152).

\section{Gendered 'Time Management' in Prior Studies}

The concept of gender and time are often implicit and invisible in daily organisation practice, and differences in time allocations are gendered and resulted into pay inequality between men and women that led to unequal distribution of power between the two genders (England, 2011). Time allocation is a reference to the time divided between work activities and home/domestic duties or leisure activities. Previous studies claimed that there is evidence when women earn more, it lowers their housework, giving them power (see Gupta, 2007). However, other evidence shows that women's earnings are not necessarily giving power in marriage or increasing their male partner's housework (Evertsson $\&$ Nermo, 2004). Thus, family duties such as domestic labour and providing care for children and the elderly at home have appeared to be significant factors that have created the discrepancy in time allocation between women and men, since these domestic duties are more often performed by women rather than men. Thus, even in Western countries, domestic work is still seen as a "femalenormative" and paid labour as a "male-normative" (Cast and Bird 2005).

The gendering of time allocation has increased with the introduction of part-time jobs as more women seem to be forced into this work pattern since they carry out domestic work and child care (Jacobs \& Gerson, 2005). Global conditions such as the new emphasis on flexibility have resulted in emphasis on temporary work; and technological developments have resulted in a '24/7' work philosophy. These factors have put both women and men under pressures in their lives. However, it was women (with no proper choice) who were more interested in achieving work/ life balance, accepting more part-time work which resulted in less gender equity in the workplace. Women who chose to have full-time work had to squeeze their family time and leisure time. This is not the same for men, and therefore, Lopez-Claros and Zahidi, 2005:2) claim that:

the reality is that no country in the world, no matter how advanced, have achieved true gender equality, as measured by comparable decision-making power, equal opportunity for education and advancement, and equal participation and status in all walks of human endeavour.

In doing both domestic work and paid work, women have experienced geographical isolation, inflexible work-site schedule, or limited family support (Osnowitz, 2005). Women's work seems to operate within two temporal orders: regulated by measurable productivity, and the other by expectation for availability and care. This has been often argued as leading to the fragmentation of women's time; and hence, it could be argued that the social organisation of time has produced gender inequality. Again, in accommodating domestic duties, some women have taken home-based contract employment, yet this requires them to exercise care to distinguish the boundaries between paid work and unpaid work.

Compressing time through flexibility was argued to be more in favour of the employer (Sabelis et al., 2008), creating new patterns of power and politics (Purser and Hassan, 2007). The "working time" adjustments have maintained gendered engagement: male part time employment is concentrated among students and older workers approaching retirement (Fagan and Walthery, 2014). The proportion of fathers who request part time work is lower than the take-up by mothers (Fagan et al., 2008). For this work pattern, employers have often used the rhetoric of 'choice' (Stone, 2007), but the reality is - women are indirectly forced to accept part-time jobs since they are motivated by their need to accommodate childcare and household responsibilities (Webber \& Williams, 2008). For employers, the ideal worker norm is one that only men are able to approximate (Correll et al., 2007), and who can devote themselves to their careers, work extremely long hours, and require minimal accommodation for their personal lives. Therefore, Bennetts (2007) has deemed parttime work schedules as a further institutionalization of the gender division of labour that intensifies the glass-ceiling effect - the invisible barrier that prevents women getting into top management positions. On the other hand, the increase in part time jobs seems to be due to the companies' needs to reduce their labour costs more than the choice or needs of their employees. Even when working times for women with childcare commitments are reduced in some family-friendly organisational policies, other issues of concern have risen, such as: whether or not their working hours are regular, predictable and controllable, which depends on whether or not they were employed in the unionized, protected segment of the labour market, as claimed by Bouffartigue (2010: 223).

In brief, research has shown that men and women continue to think of family life and domestic work in very different ways. This can be seen in the very slow pace of change in the distribution of domestic work and parenting between the sexes. In fact, women's time is a qualitatively different temporality from men's, in particular because the mental burden associated with domestic work goes well beyond the spatial and temporal boundaries of the domestic sphere (Haicault, 1984: cited in Bouffartigue, 2010). Here, it can be argued that in the past, time was institutionalised by cultural norms and legal systems. At present, modernity has created new institutional rules and power relations that control time allocation.

\section{Data Findings: Analysis \& Discussion}

This study has been based on the personal perceptions and experiences of eight Syrian women doing paid work - who have been interviewed face-to-face to elaborate on semi-structured, open-ended questions with an interviewing time ranging between one and two hours. Using the discourse analysis theory, the findings have been thematically identified and classified under the notion of time, awareness of boundaries between public and private spheres, and the gendering of time management. The analysis of the data findings has been based on Foucault's thinking that discourse cannot be analysed only in the present, because the power components and the historical components have created such a tangled knot of shifting meanings, definitions and interested parties over periods of time (Powers, 2007: 26). Accordingly, the empirical findings have been analysed and discussed in relation to the issue of gender inequality that is derived from the concept of power. For Foucault, this power does not exist apart from economic relations, political relations, knowledge relations, or sexual relations, but is inherent in them (Powers, 2007: 30). The interview questions were designed to capture the main activities during time before work, time at work, and time after work. The major pivotal themes focus on exploring women's time management strategies, which are driven by various factors, such as: economic factors (household financial needs, low wages), personal factors (belief, ideology, up brining, education, generation), socio-cultural factors (religion, social norms, ethics), and environmental factors (workplace, husband's work, children, accommodation). 


\section{Key Notions of Time}

Time was thought of as an external reality that needs to be dealt with objectively. For instance, one of the participants pointed out how she regards time as her enemy against which she needs to win a battle: "Time is like a sword -if you couldn't cut it, it will cut you". Other participants talked about saving time, wasting time and racing against time: "Time is like a train that keeps moving fast, no stopping, and we need to catch it", as Ghada pointed out. This indicates a view on the scarcity and value of time as a resource and the understanding of its characteristics, such as speed and temporality. Some participants reflected on the ability of possessing time and spending it in doing something useful: Ghada (an administrator and a mother) stated:

My kids do not appreciate time... I need to remind them all the time, how they need to use it in something useful ... they need to divide it between play, study and rest.

Although the participants talked about time as a linear, quantifiable and commodified clock-time, the tone of their conversation also reflected a cyclical view of time, which denies human agency and regards people as structured beings with no control over time. Jalaa (the bank manager and mother) explained:

To be honest I sometimes feel like a machine or something drifting around with no control over my time ... I keep doing the same thing again and again ...I don't know when and where to stop.

Batta (Lecturer) has also bluntly made the distinction between paid work in the workplace and unpaid domestic work in terms of linear time and cyclical time.

The husband can allocate some of his time to care for the children...especially when I have important meetings or deadlines...but you know... domestic work and caring for children is different from work schedules...it is not a one-off activity...it is an ongoing process that needs to be done even if I chose a paid job outside the house.

Thus, unlike paid work, caring and domestic work activities have to be repeated over and over again without ever reaching an identifiable end point. These activities are often woven into other processes, involving multi-tasking or polychronic rather than monochronic time (see Bryson, 2007). Here, the focus is on the present and the context of the task, unlike the linear time, which shows an interest in the future and the de-contextualisation of the task.

They also expressed an awareness of the harsh reality of time represented by its acceleration, as one participant, Sawsan - a medical doctor with no children claimed:

Time is riding a very fast chariot and we are trying to seize it but in vain... everything rounds me is moving fast ... but I feel very slow... my time is always running out ... whether at work or at home.

It was also evident in the interviews that time was regarded as a limited resource whose value comes from the fact that it cannot be increased or extended. All participants reflected on the significant value of time and their appreciation of this value but through various techniques. For example, some participants were keen on completing as many tasks as possible within a specific time span, while others tried to use technology or prioritisation. For instance, through her adherence to a polychronic culture of dealing with the notion of time, Ghada explained very proudly showing off her multitasking skills:

I very often help kids in their homework while I'm cooking or ironing, you know if I don't do it this way I cannot manage my time properly...It is different at home ... I can do so many things within a time span... At work I need to do things in a more organised manner. it is not as stressful as my house and caring work.

Ghada's view was also repeated in all other interviews. This reflects coexisting references to monochronic thinking and polychromic thinking of the notion of time and its management. As for her children, Ghada needs them to learn how to do things one at a time as a way of achieving efficiency of work which is similar to the one needed in the workplace. As for the domestic work at home, efficiency means managing all the tasks within a specific time limit. Having said that, it can be argued that the participants seem to be operating within two different time cultures, which leads them to delegate some of their domestic and care work to others, if there is a possibility to do so, as clearly manifested by Ghada's statement:

You don't believe that ... I sometimes and while at work I instruct my daughter how to make simple cooking and how to help her brother in his schoolwork... I don't have enough time for that.

Moreover, the indication of this statement goes further to reflect the sense of fragmentation experienced through the interference between the time dedicated for public sphere (workplace) and that of the private sphere (housework). The assumption here is that the daughter's time should be spent in care rather than the son's time. Ghada did not ask the husband or the son since she has already expressed in another statement that housework and childcare is naturally expected to be done by females rather than males, and she also justifies it as a socio-cultural norm in Syria:

Come on .... this is not a man's work... next time you may ask him to change nappies not only making bed. It is a wishful thinking... yes, he helps but not in doing those little trivial things...I need to do these things .... You know men can't be trusted to do them efficiently ... in fact they do not have the time. I'm mostly at home rather than he is.

This indicates that participants referred to an intricate relationship between the gendered characteristics and use of time. Again, domestic and caring work is not only undervalued by men but also by women, since Ghada's husband's time is more important and more valuable so that it should be spent all on paid work outside the house. Although Ghada demonstrates a belief in gendered time allocation, she does not see it this way or even she does not recognise any sense of inequality.

Ghada goes further to assert that the husband's time at home could be spent on things that need more authority:

Yes, when it comes to problems with the boys, I ask him for help... men are much better at making the tough talking and taking firm actions .... But only if he has got the time for this. Even, when it is a holiday time, it seems that Ghada and her husband divide their times differently:

He invests more time for planning our holidays, but I do all the necessary preparations: packing the suitcases, ensuring that everything needed is there... although this takes much more time than planning".

\section{Discursive Constructions of Boundaries}

As seen above, participants have noted that the home and the workplace are two very different fields and that each field has a different logic, organisation and time rhythm. For them, domestic work and care work require the feminine competence which men do lack, and the workplace requires masculine competence which women are trying to get by adopting assimilation strategies (Miller \& Karakowsky, 2005). For instance, Sawsan (a highly educated and professional woman) has denied the existence of gender inequality in her environment and avoided sex stereotyping and tried to mask her femininity. She did not recognise any overlap between her private time and public time, but she also stated:

Of course, if I have children, I would phone the house during my work time to see if they are OK, but I don't expect that my husband would do.

On the other hand, Sawsan did not agree that women are passive in dealing with time and its allocation:

It is up to me whether to be a mother only or both a mother and an employee ...I can choose jobs that allow me to do both... but if I had a full-time job in an organisation, I need to make some compromises",

In fact, her words "it is up to me" asserts that she is an agent who has got a choice, but this is not the case since she can be seen as forced into accepting such a situation: she is doing this because of having children not because she has a choice. Additionally, the statement indicates her belief that the public should be kept from the private in full-time jobs, she is not aware of any interference between them in such a case; however, she doesn't mind the overlap between the two in a contract or part-time work. This is an indirect insinuation that women are not able to manage their time properly in case of professional full-time job without making some compromises or paying some penalties. She also denied that 
coping with time management between the home and the workplace is a stressful thing, claiming:

It is all to do with my choice: I can choose to sit at home if my family need more of my time. As a woman, I would say family/children come first, and work comes next.

Although Sawsan denied inequality in time management, she emphasised that her time rather than her husbands should be dedicated mostly and firstly to her children and domestic needs. This is an admission that she cannot control her time as much as her husband can do, and that the time she spends on care work will hinder the time spent at work. This was confirmed by another participant (Jalaa, with little children, bank manager) by saying: Sometimes, I can hardly cope, especially if my youngest (6months old) was awake all night ...I wouldn't have enough sleep....interrupted sleep kills me and I cannot have my head round things the next morning ....of course this affects my work and I'll be very sleepy in the workplace" It would help if I could have a part time job.... but I need the money more than anything else".

The fragmentation of women's time and the blurring of boundaries were quite obvious in nearly all interviews, where participants confirmed that it is very difficult to have leisure time in the real sense of the term (unplanned time). One of the participants commented:

There is nothing spontaneous any more... even the leisure time should be planned... you should fill it with some kind of work that you kept delaying until you have some holiday. I take kids to theme parks, or carry out some social duties and visits or do some extra housework ...I sometimes try to learn new skills that are needed for my work...

This indicates that participants understand that every planned or managed time is not counted as leisure time. The idea of leisure time seems to be a myth or a mirage that working women keep wishing to have. This is what might be called the gendering of time management, as discussed in the following section.

\section{Gendering Time Management}

Part-time work seems to be the overwhelming theme for managing women's time in the data of this study. Other than dropping out of their jobs, at the stage of forming a family, many women seem to change into part time work (see Griffiths and Moore, 2010) because they experience a dilemma in dividing their time between work commitment and their private lives (see Castaño et al., 2010). Women with children seem to be much more likely to exhibit such tendency, especially in the years of maternity which coincide with the decisive years in careers development (Caprile et al., 2011). This situation seems to be culturally and socially bound since men in the Syrian culture are looked at as the main bread winners of the family, and hence, their time is more valuable and has to be consumed fully in the production process in the workplace. This idea was quite prevalent throughout all interviews, as Ghada clarified:

Right from the start, we agreed that it has to be part time not full-time work ... I'm more needed at home as I have little ones" ... all women we know do it like this way. He was more concerned about it. he doesn 't want me to over work myself This statement indicates the assumptions that part time work is gendered, and that it is not a choice. Although the participant is using the word 'agreed', there seems to be a tendency that women are predestined for allocating more of their time rather than men to domestic and care work. This tendency seems to be more in favour of the male and more justified by the social norms expressed in the phrase "All women we know do it like this way". Again, Ghada saw this concern of the husband over her not doing too much work as a good intention on his part. However, it could be argued that if he was concerned, he should have increased his time for helping in domestic duties rather than expecting her to perform them. This also indicates the little or no value the husband is attributing to her work. It is a woman's responsibility to achieve work-life balance. Women seems to seek flexibility as a kind of autonomy, but this is not the case since flexibility is more beneficial for the employer, the husband and the children (see Sabelis et al, 2008).

The participants did not seem to recognise that the time spent on care and domestic duty as the reason behind women's segregation into less desirable low paid and part-time jobs. They attributed this trend to the presence of masculine occupational work culture - Hazar (administrator with children, no partner) explained: Good jobs and high positions need special contacts and special qualifications that women are not interested in ... women's priority is marriage and children as these would give the autonomy and independence .... Come on! You know that women cannot compete with men in our society... they are not as aggressive as men".

In fact, women who took time off to care for families lamented that when they returned to work, they lost their personal network and their self-confidence (see Herman and Webster, 2010). Batta (lecturer, children, no partner) did not like going back to her job as it was changed into a part-time one. Similarly, Batta was aware of her time management limitation and how this makes her stand on uneven grounds with men whom she competes with at work. She also recognises that the time spent on care and domestic duty as the reason behind women's segregation into less desirable low paid and part-time jobs. Another high-positioned participant (Jalaa) expressed disappointment when she went back to work after taking a gap:

The time I have spent during maternity years has clearly hindered my advancement in job .... I did not have any support ...my husband emphasised that children are a priority and my time should be fully dedicated to them. He saw work time as a waste, and that it does not contribute to the well-being of the family financially or otherwise".

In this case, one could argue that Jalaa's action was prompted by the masculine ideology expressed by her husband and supported by the social and cultural norms. So, Jalaa has pursued of different techniques to control her work time, thinking that she has had a choice in this, as a high earner - she pointed out:

I lost touch with the realities of employment, I didn't have my skills up to date...I could have postponed my maternity like other professional women, but I chose not to .... As maternity has its time perspective... let's say I cannot control it for good. However, Jalaa seems to have been affected by her biology and her own whims to conform to her culture by exercising her motherhood: in Syria, women's priority is marriage and children - it is believed that these are the things that give autonomy and independence to women.

Other participants expressed different perspectives on the issue of time control, indicating that working women could buy out their time if they can afford to; Sawsan argued:

the problem of women's time management is not purely associated with children ... it is more to do with the number of children and how old they are - as they grow older they need less attention ... some women receive help but this could be arranged with or without payment".

In the case of Batta, the solution was there:

"...as my husband was a freelancer, he helps in getting the laundry done, going to store and picking up the kids from school... however, he manages preparing his own breakfast but not the kids... This is a weight off my shoulders".

But Ghada stated that neither her religious beliefs nor her morality/ethics allow her to neglect her family duties for the sake of dedicating more time for her job, justifying vigorously her gendered duty towards her kids:

no one can provide them with the quality of care they need except the mother ... men are not meant to do it as such".

But she emphasised that her time is driven by the economic needs of her family:

I had to work very long hours even I had children, the husband wasn't working ... but we have a lot of financial commitments... Yes, my job doesn't pay that much but this is what's available on the market...I don't like to commute to long distances... my time is already killed at work.

Again, she lamented her workplace as it doesn't allow any worklife balance or work time flexibility:

"I'm the only one to cater for customers' needs... this is very demanding... when I'm away, the boss has to step in and he is such a pain when it comes to this".

Part time work wasn't the only technique adopted by the participants to handle the issue of time management. In generating more time to themselves, some women have delegated parts of domestic work to their children or/and their husbands. In 
other instances, professional and high-positioned working women paid someone to do their domestic and care work, as their social and financial positions allowed to.

The participants have demonstrated that a woman is expected be everywhere at the same time, caring for everyone except her own self: "Being a mum means you are stripped of yourself and your time”, pointed out by Batta (a divorcee lecturer). This understanding is driven by organisational culture, governmental policies and society, Jalaa said:

Your boss, the laws and even your peers would expect you to have this caring role at home.

It is a woman's job to achieve work-life balance, adhere to traditions, customs and biological views in regard to women's role in society - as confirmed by Sawsan:

it is our duty as women to priorities our time for children, husbands and housework.... it is against the norms to do it otherwise ... we have been brought up like this...

Participants have tried to move between timelessness required by the workplace (spend as much time there as needed) and timeliness required by the home (things have to be done at certain times) (see Bunting, 2011), which led them to the overwork culture. All participants seemed willing to put more work hours when they need the money or a decent future pension. On the other hand, they have clearly indicated how the extra time spent at work has negatively affected their family life. Participants with children have commented in a similar manner to Jalaa's view: In these hard times you need to clinch to your job with your teeth... we cannot afford redundancy.... Kids do suffer.... I'm doing longer hours than I used to -the husband doesn't like it but there is no other option.

Even a participant with no children (Sawsan) have followed suit in conforming to the overwork culture:

Doing extra work is always welcomed by my employers ... it enhances my image of loyalty, but it is also good for future promotion or even for my pension...

The attitudes to how Syrian women manage their time seems to differ across the same culture, from individual to another and from time to time. Some interviewees clearly pointed out such an attitudinal change, using the phrase - "things now are different from past times". This has a connotation that some working women are not passive towards the issue of time management and the gendering of time use - they challenged temporal assumptions by making their work time a priority rather than prioritising their unpaid/ domestic work time, as indicated by Hazar:

the time you spend at work and hence your pension is what you have to think of. It is not like past times."

The view expressed by the younger generation of participants was represented in one interviewee's (Dalia) statement, which sounded as if trying to justify some sort of a guilt felt against her cultural and social norms:

...women should hold onto their employment tight because this is what will help them to satisfy their needs and ambitions especially in these modern times ... we are not like our parents'generation."

This reinforces the view that devalues domestic and care work even by some women. This could be taken as a change in women's attitude towards time management. Consequently, highly skilled and younger women started managing their time differently from those women of less valued job roles. Modern times require them to be tough, competitive and economically independent. Laila pointed out:

Having a university degree does not mean wasting your time at home doing the little tiny things here and there.

Thus, educational and financial status does affect women's time allocation and can justify their break away from normative gender-appropriate behaviours in regard to time management between work and home. On the other hand, this kind of behaviour or thinking was often rebuked by society and other family members, or looked at as something that needs to be negotiated rather than being within women's choice, as claimed by a participant (Ghada):

My husband and kids can manage some other housework without any complaints... we have divided the work between us... they do not mind that I do longer hours at work.
Casual workers could not afford it so they ended up dedicating more of their time for their house work, even if their husbands were prepared to do some of that domestic work, but not with the same persistence and consistency as women did - Jalaa said: My husband helps but not all the time ... he doesn't expect it to go on for good... he doesn't always have time for this “ In sum, all participants believed that they can exercise a degree of autonomy and the culturally expected femininity through managing their time which is dedicated to domestic and caring work. They also showed a belief in the division of labour and sharing duties with their partners but without properly recognising how much of their time was committed towards the family in work that is neither paid for nor formally recognised.

\section{Conclusion}

The data collected suggested that not all participants were able to make an intelligent or informed distinction between public and private spheres (see Lister, 2007 and Zelizer, 2005). However, all of them clearly indicated that their domestic responsibilities often prevent them from entering the public sphere on the same terms as men, and that gender inequalities are rooted in unequal time use within the home. For those women, work is conventionally understood as paid work in the public sphere, although they acknowledged that their unwaged activities at home seem central to the survival and well-being of their society. The time spent by the participants on non-work or unpaid activities was never thought of as something to be measured, valued or paid for. This could be argued to have affected or was affected by the Syrian work policies, which do not recognise the time-consuming nature of domestic tasks, ignoring the economic and social importance of unpaid (private) work. The attempt to blur the boundaries between public and private life is aggravated by the fact that domestic and caring work is paid for only if it takes place outside the home (see Zelizer, 2005).

The working women in this study have shown differences in dealing with their time, how they structured their time, and the degree of autonomy to do so. They also demonstrated differences in their temporal bargaining positions in their own homes and in their subjective perception of time itself. This was an outcome of their relationships to the public and private spheres. For instance, the working hours of the casual workers were often long, fragmented, irregular and often merged with their own domestic duties. They couldn't perceive the distinction between working and non-working times; and they did not - at all times - expect or receive any help from their husbands in their domestic work. In contrast, women in high positions were able to pay for someone to do the domestic work and childcare, and they expected to receive help from their husbands. They also recognised their domestic arrangements as private issues, but they have moved them into the public sphere through paying someone to do them. In more general terms, all participants confirmed that attending to personal needs is not always reduced to a list of activities and made to conform to the logic of clock-time. They also confirmed that providing a temporal structure for domestic and caring activities is often both necessary and valuable. Their work at home seems to generate time for other members of the family they co-ordinate the family's activities with external timetables of schools, dentists, transport and other household tasks (see Gray, 2003).

As for working women with lower job roles, they have experienced some sort of 'time poverty', since they do not have any 'discretionary time'- which can be an indicator of 'temporal autonomy' - as identified by Goodin et al. (2008). However, research has often found that whenever women go to work, they end up doing both paid and unpaid labour (Bryson, 2007; Birch et al., 2009); and hence, it can be argued that necessary time in paid and unpaid labour is not exchangeable and this leads to a sense of inequality between working men and working women. To sum up the position of working women in Syria in relation to time management, I will refer to Forman's (1989:1) statement:

Regardless of circumstances, women are strangers in the world of the male-defined time and as such are never at home there. At best, they are like guests eager to prove helpful; at worst they are refugees living on borrowed time. 
As the data suggested unequal conditions for working women, justice can be achieved by redistributing the time spent on unpaid labour within the family, as advocated by Okin (1990: 4):

Until there is justice within the family, women will not be able to gain equality in politics, at work, or in any other sphere.

In this respect, it is often argued that women whose mobility is restricted by the need to care for others can never gain full autonomy, as advocated by Fraser (1997:133):

“autonomy may not necessarily result in 'equality' in gender relations without relevant state interference for social protection and redress for gender power relations.

To progress in terms of gender equality in relation to time allocation, solutions are needed to challenge the long hours of work and men's lack of commitments to domestic responsibilities. State regulation is required in many high-income countries (for example: Italy, Japan, Spain, and Switzerland) where care provision is left to the family without effective state intervention (Eddyono et al., 2016). Moreover, paid and unpaid care work and domestic work should be included in governmental statistics. It is claimed that paid care work, especially domestic work, has been excluded from the scope of formal labour market and national labour laws (Maclaren, 2009).

Finally, the most important normative measure that can be taken by states is to narrow the wage gap between men and women. As for Syrian working women, their participation in political decision-making positions in public life should be promoted, and all discriminatory articles in the Personal Status Law and the Penal Law should be amended in a way that regain women's position in society as equal to men.

\section{References}

i. Adam, B. (1995). Timewatch: The Social Analysis of Time. Cambridge: Polity Press.

ii. Adam, B. (2004). Time. Cambridge: Polity Press.

iii. Amanatullah, E. and Morris, M. (2010). Negotiating gender roles: Gender differences in assertive negotiating are mediated by women's fear of backlash and attenuated when negotiating on behalf of others. Journal of Personality \& Social Psychology, 98(2): 256.

iv. Ancori, B. (2019). The Carousel of Time: Theory of Knowledge and Acceleration of Time. John Wiley \& Sons.

v. Bennetts, L. (2007). The feminine mistake: Are we giving up too much? New York: Voice/Hyperion.

vi. Birch, E., Le, A., \& Miller, P. W. (2009). Household divisions of labour: Teamwork, gender and time. Springer.

vii. Bluedorn, A. C. (2002). The Human Organization of Time: Temporal Realities and Experice, California: Stanford University Press.

viii. Bouffartigue, P. (2010). The Gender Division of Paid and Domestic Work: Some remarks in Favour of a temporal perspective, Time \& Society, 19: 220 - 238.

ix. Bryson, V. (2007). Gender and the Politics $f$ Time: Feminist Theory And Contemporary Debates. Bristol: Policy.

x. Bunting, M. (2011). Willing slaves: How the overwork culture is ruling our lives. HarperCollins UK.

xi. Calabrese, M., Iandolo, F., Caputo, F., \& Sarno, D. (2018). From mechanical to cognitive view: The changes of decision making in business environment. In Social Dynamics in a Systems Perspective (pp. 223-240). Springer, Cham.

xii. Caprile, M., Meulders, D., O'Dorchai, S., \& Vallès, N. (2011). Introduction to the Special Issue. Gender and Science: Old Challenges, New Approaches. Brussels Economic Review, 54(2-3), 108-129.

xiii. Cast, A. D., \& Bird, S. R. (2005). Participation in household and paid labor: effects on perceptions of role-taking ability. Social psychology quarterly, 68(2), 143-159.

xiv. Castaño, C., Martín, J., Vázquez, S., \& Martínez, J. L. (2010). Female executives and the Glass Ceiling in Spain. International Labour Review, 149(3), 343-360.

xv. Correll, S. J., Benard, S., \& Paik, I. (2007). Getting a job: Is there a motherhood penalty? American journal of sociology, 112(5), 1297-1338.

xvi. Eddyono, S. W., Fanani, E., Sabaniah, D. A., Maurice, Y., Ghazali, H., Warlif, J., ... \& Ciciek, F. (2016). When and why the State responds to women's demands: understanding gender equality policy change in Indonesia. United Nations
Research Institute for Social Development. Accessed February 12, 2019.

xvii. England, Paula (2011) Reassessing the Uneven Gender Revolution and its Slowdown. Gender \& Society, 25: 113 123.

xviii. Eriksen, TH (2001) Tyranny of the Moment: Fast and Slow Time in the Information Age. London: Pluto Press.

xix. Evertsson M, Nermo N. (2004) Dependence within families and the division of labor: comparing Sweden and the United States. J Marriage Fam.Vol.66, pp:1272-1286

xx. Fagan, C., \& Walthery, P. (2014). Working time capabilities at the workplace: Individual adjustment options between fulltime and part-time working in European firms. Work-life balance: The agency and capabilities gap, 174-205.

xxi. Fagan, C., McDowell, L., Perrons, D., Ray, K., \& Ward, K. (2008). Class differences in mothers' work schedules and assessments of their 'work-life balance'in dual-earner couples in Britain. Women and Employment: Changing lives and new challenges, 199-212.

xxii. Forman, F. J. (1989). Feminizing time: an introduction. Taking our time: Feminist perspectives on temporality, 1-9.

xxiii. Fraser, Nancy. (1997). After the family wage: A postindustrial thought experiment. In Nancy Fraser, Justice Interruptus: Critical reflections on the "post socialist" condition (pp. 41-68). New York/London: Routledge.

xxiv. Gell, A. (2000). 'Time and Social anthropology'. In P. Baert (ed) Time in Contemporary Intellectual Thought, Amsterdam: Elsevier, pp: 251-68.

xxv. Goodin, R. E., Mahmud Rice, J., Parpo, A., \& Eriksson, L. (2008). Discretionary Time: A New Measure of Freedom. Cambridge University Press.

xxvi. Goudsblom, J. (2001) The worm and the clock: on the genesis of a global time regime, in W. Schendel and H. Nordholt (eds) Time Matters: Global and Local Time in Asian 36. Societies, Amsterdam: VU University Press, pp: 19-

xxvii. Gray, D. E. (2003). Gender and coping: The parents of children with high functioning autism. Social science \& medicine, 56(3), 631-642.

xxviii. Greenhaus, J.H. and Powell, G.N. (2003) When work and family collide: deciding between competing role demands. Organizational Behaviour and Human Decision Processes, 90,2, 291-303.

xxix. Griffiths, M., \& Moore, K. (2010). 'Disappearing Women': A Study of Women Who Left the UK ICT Sector. Journal of Technology Management \& Innovation, 5(1), 95-107.

xxx. Gupta, Sanjiv. (2007). Autonomy, dependence, or display? The relationship between married women's earnings and housework. Journal of Marriage and Family, 69:399-417.

xxxi. Haicault, M. (1984) 'La gestion ordinaire de la vie en deux' (The Ordinary Management of Life as a Twosome), Sociologie du Travail 3: 268-89.

xxxii. Hall, E. (1990) Understanding cultural differences. Yarmouth: Intercultural Press.

xxxiii. Hassan R (2003) Network Time and the New Knowledge Epoch. Time \& Society, 12(2/3): 225-41.

xxxiv. Hassan, Robert (2009) Empires of Speed: Time and the Acceleration of Politics and Society. Leiden: Brill.

xxxv. Hassard J (2002) Essai: Organizational Time: Modern, Symbolic and Postmodern, Reflections. Organization Studies, 23(6): 885-92.

xxxvi. Herman, C., \& Webster, J. (2010). Taking a lifecycle approach: redefining women returners to science, engineering and technology. International Journal of Gender, Science and Technology, 2(2).

xxxvii. Hochschild, A. R. (1997): The Time Bind. When Work becomes Home and Home becomes Work. New York: Metroplitan Books, Henry Holt \& Co.

xxxviii. Hofstede, G. (1980/2001) Culture's Consequences: International Differences in Work-related Values, 2nd edn. Beverly Hills, CA: Sage. 
xxxix. Jacobs, J. A. \& Gerson, Kathleen (2005). The time divide: Work, family, and gender inequality. Cambridge, MA: Harvard University Press.

xl. Linstead, S. (2009) Managing Culture. In Linstead, S., L. Fulop \& S. Lilley (eds.) Management \& Organization: A Critical Text. 2nd ed. Basingstoke: Palgrave Macmillan.

xli. Lister, R. (2007) Citizenship, in G. Blakeley and V. Bryson (eds) The Impact of Feminism on Political Concepts and Debates, Manchester: Manchester University Press, pp: 7995.

xlii. Lopez-Claros, A., Zahidi, S., \& Forum économique mondial. (2005, May). Women's empowerment: Measuring the global gender gap. Geneva: World Economic Forum.

xliii. Maclaren, Barbara. (2009). Excluded workers, excluded women: Challenging the marginality of domestic work in Latin America. Focal Point, 8, available at: http://www.focal.ca/pdf/focalpoint_se_april2009.pdf

xliv. Marcus, A. \& Gould, E. (2000), Cultural dimensions and global web user-interface design: What? So what ?Now what?www.tri.sbc.com/hfweb/marcus/hfweb00_marcus.htm 1

xlv. Miller, D. L., \& Karakowsky, L. (2005). Gender influences as an impediment to knowledge sharing: When men and women fail to seek peer feedback. The Journal of psychology, 139(2), 101-118.

xlvi. Newell, HJ and Scarbrough, H. (2002) Human Resource Management in Context: A Case Study Approach. Houndmills, Baskingstoke: Palgrave.

xlvii. Okin, S. (1990) Justice, Gender and the Family, New York: NY Basic Books.

xlviii. Osnowizt, Debra (2005) Managing Time in Domestic Space: Home-Based Contractors and Household, Gender and Society, Vol. 19 (1), pp: 83-103.

xlix. Powers, Penny (2007) The Philosophical Foundations of Foucaultian Discourse Analysis, Critical Approaches to Discourse Analysis across Disciplines 1 (2): 18-34

1. Prokhovnik, R. (2002) Rational Woman: A Feminist Critique of Dichotomy ( $2^{\text {nd }}$ edn), Manchester and New York, NY: Manchester University Press.

li. Purser, Ron and Hassan, Robert (2007) Time in the Network Society. Stanford, CA: Stanford University Press.

lii. Putman, R. (2000) Bowling Alone: The Collapse and Revival of American Community. New York: Simon \&Schuster.

liii. Rosa, Hartmut and Scheuerman, William E. (eds) (2009) High-Speed Society: Social Acceleration, Power and Modernity. Philadelphia: Penn State University Press.

liv. Sabelis, I. (2004) Global speed — a time view on transnationality. Culture and Organization, 10,4, 1-11.

lv. Sabelis, I; Nencel L.; Knights, D. And Odih, P (2008) Editorial: Questioning the Construction of 'Balance': A Time Perspective on Gender and Organization, Gender, Work and Organization, Vol. 15 (5):423-429.

lvi. Scheuerman, W. E. (2020). Liberal democracy and the social acceleration of time. JHU Press.

Ivii. Simard, C, Henderson, AD, Gilmartin, S, Schiebinger, L an d Whitney, T. (2008). Climbing the technical ladder: Obstacles and solutions for mid-level women in technology, Boulder, CO: National Center for Women and Information Technology, University of Colorado.

Iviii. Solomon, Charlene and Schell, Michael (2009) Managing Across Cultures. New York: McGraw Hill.

lix. Steers, Richard; Sanchez-Rund, Carlos; and Nardon, Luciara (2010) Management across Cultures: Challenges and Strategies. Cambridge: Cambridge University Press.

Ix. Stone, Pamela. (2007). Opting out? Why women really quit careers and head home. Berkeley: University of California Press.

lxi. Thompson, E. P. (1999 [1967]) Time, work-discipline and industrial capital, in E.P. Thompson (ed) Customs in Common, London: Penguin Books, pp: 352-403

lxii. Warf, B. (2017). Time-space compression and the remaking of European topologies. In The Routledge International Handbook of European Social Transformations (pp. 253268). Routledge.
Volume IX, Issue II, 2020, 28-35

Ixiii. Webber, Gretchen and Williams, Christine (2008) "Mothers in "Good" and "Bad" Part- Time Jobs: Different Problems, Same Results". Gender \& Society, Vol. 22 No. 6, pp: 752-777.

lxiv. Weber, M. (1999). Essays in economic sociology. Princeton University Press.

lxv. Ylijoki, Oili-Helena (2010). Future orientations in episodic labour: Short-term academics, Time Society, Vol.19 (3): 365-386.

Ixvi. Zelizer, V. (2005) The Purchase of Intimacy, Princeton, NJ: Prinston University Press. 